\title{
Relationship between Brain Hemisphericity and Non-routine Problem Solving Skills of Prospective Teachers
}

\author{
Yeliz Yazgan*, Hatice Busra Sahin \\ Education Faculty, Uludağ University, Turkey
}

Copyright(C2018 by authors, all rights reserved. Authors agree that this article remains permanently open access under the terms of the Creative Commons Attribution License 4.0 International License

\begin{abstract}
The present study aims at answering the question of whether there is any relationship between brain hemisphericity and non-routine problem solving skills of prospective teachers. One hundred twenty-three prospective teachers participated in the study. The Brain Hemisphericity Test and Non-routine Problem Solving Test were used to evaluate participants' brain dominance and achievement in solving non-routine problems. Spearman Rank Correlation Test results showed that there is no link between cerebral dominance and success in non-routine problem solving. This finding may imply that left- or right-brained students can be equally successful in non-routine problem solving. Besides, it can be encouraging to use non-routine problems in math teaching without any limitation in the sense of brain dominance.
\end{abstract}

Keywords Brain Hemisphericity, Brain Dominance, Non-routine Problem, Problem Solving

\section{Introduction}

The brain is the master controller of a network that transmits and controls any information sent to and from the other areas of the body [1]. It consists of a great number of neural networks, and the complexity of these neural networks determines the level of thinking ability from the low order thinking skills to high order thinking skills such as critical, creative, logical, analytical, and reflective thinking ability. Moreover, problem solving closely relates to the activity of thinking while the activity of thinking is an activity of the human brain [2]. Based on this, it can be said that the quality of neural networks in the brain affects individuals' problem solving skills as well. Therefore, recent findings on properties of the brain have stimulated debates on whether such findings provide a meaningful contribution to mathematics education, specifically mathematical problem solving [3].

Specific facets of the brain and problem solving are to be synthesized here, so there are two main components of this study: Brain hemisphericity and non-routine problem solving. The first component, brain hemisphericity (a.k.a brain dominance, cerebral dominance or brain laterality), refers to the idea that people rely on a preferred mode of cognitive processing that is linked to predominant activity of either their left or right cerebral hemisphere [4]. As summarized by Oxford, Ehrman \& Laviner [5], the left hemisphere operates in a linear, sequential manner with logical, analytical, prepositional thought, and is specialized for language and also controls the right lateral side of the body. Hence, left-hemisphere dominant individuals are analytical, verbal, linear and logical learners. On the contrary, controlling the left lateral side of the body, the right hemisphere operates in a non-linear, simultaneous fashion and deals with non-verbal information, and is specialized for visuo-spatial thought. Right-hemisphere dominant individuals tend to be highly global, visual, emotional and intuitive learners. However, as Roubinek, Bell, \& Cates [6] stated, the fact that people tend to have a preference for either the left or right hemisphere does not mean that they do not use both hemispheres. Instead, both hemispheres are involved in processing of information.

Some researchers assert that cerebral dominance is the result of genes, while others contend that it is the result of cultural and educational practices [7, 8]. Taking the second side, Saleh and Iran Nejad [9] state that brain hemisphericity is an acquired mode of thinking through schooling and cultural practices that emphasize and value the left hemisphere's analytical abilities. This also explains the failure of right-hemisphere dominant students who are unable to adapt to their school's analytical and global practices. According to this viewpoint, activities in which both hemispheres are actively involved may help to overcome this imbalance in the learning environment [9].

Equally important in the learning process is developing 
competence in solving non-routine problems. Non-routine problems are the kind of problems which are most appropriate for developing mathematical problem-solving and reasoning skills, and the ability to apply these skills in real-life situations [10-12]. Routine problems can be solved using methods familiar to students by replicating previously learned methods in a step-by-step fashion, while non-routine problems are problems for which there is not a predictable, well-rehearsed approach or pathway explicitly suggested by the task, task instructions, or a worked-out example [13]. The following are examples of routine and non-routine problems, respectively:

A sales promotion in a store advertises a jacket regularly priced at $\$ 125.98$ but now selling for $20 \%$ off the regular price. The store also waives the tax. You have $\$ 100$ in your pocket (or $\$ 100$ left in your charge account). Do you have enough money to buy the jacket?

A male bee is born from an unfertilized egg, a female bee from a fertilized one. So, in other words, a male bee only has a mother, while a female bee has a mother and a father. How many total ancestors does a male bee have going ten generations back?

There are some procedures used to explore, analyze, and probe aspects of non-routine problems in an attempt to formulate pathways to a solution, and these are known as non-routine problem solving strategies [14]. In the literature, the most commonly used non-routine problem solving strategies are as follows: Act it out, look for a pattern, make a systematic list, work backward, guess and check, make a drawing or diagram, write an equation or open sentence, simplify the problem, make a table, eliminate the possibilities, use logical reasoning, matrix logic, and estimation [15-17].

Results of initial studies about the relationship between brain hemisphericity and problem solving implied that the general characteristics associated with each hemisphere of the brain also apply to mathematical problem solving. According to Creswell, Gifford, and Huffman [18], left-brained children will typically outline the problem very methodically, carefully plan each step and then solve the problem, while right-brained learners will read the problem several times, perhaps look at notes and seem to go through an idle period while mulling thoughts around, then solve the problem. With the advent of technology, most recent studies have focused on examining brain activity during problem solving by using devices such as $\mathrm{EEG}^{1}$ or $\mathrm{fMRI}^{2}[19,20]$. According to the results of these

1 Electroencephalography (EEG): Electroencephalography is an electrophysiological monitoring method to record electrical activity of the brain.

2 Functional magnetic resonance imaging or functional MRI (fMRI): Functional magnetic resonance imaging measures brain activity by detecting changes associated with blood flow. studies, there appears to be no special part of the brain that is responsible for problem solving. Rather, different brain regions may be activated depending on factors such as cognitive styles of individuals, difficulty levels of problems, thinking skills required to solve problems, and performed problem solving stage $[19,20]$.

Two independent studies carried out by Fernandez [1] and Oliver [21] are most related to the current study because they deal with non-routine problem solving and brain hemisphericity simultaneously. Fernandez [1] aimed to find out the relationships between brain hemisphericity and mathematics achievement of high school students. To determine the students' brain hemisphericity, a Hemisphere Dominance Questionnaire was employed, while the Mathematics Achievement Test was utilized to determine the level of mathematics achievement. The first part of the Mathematical Achievement Test consisted of multiple choice questions and the second part was a problem-solving section which included non-routine problems. The results revealed that the dominant brain hemisphericity was the left brain and that their mathematics achievement was "average". No significant difference existed in their mathematics achievement when classified according to brain hemisphericity.

In Oliver's study [21], associations between problem solving strategies and brain hemisphericity were examined. Participants were ninth graders and the hypothesis was that there is a correlation between the methods used to solve a single open-ended non-routine problem and the scores obtained in the Style of Learning and Thinking Questionnaire, which measures students' brain dominance. Results showed that students who have left brain dominance tended to prefer a written logical explanation strategy while students who have right brain dominance tended to prefer drawing diagrams to solve certain complexity levels of the mathematics problem.

Neither of these two studies includes prospective teachers as participants. Although one of the components is brain hemisphericity in these studies, the other one is not merely non-routine problem solving. For example, the other variable in Fernandez's [1] study is general mathematics achievement while Oliver [21] focuses on problem-solving strategies as the second variable. Distinct from these studies, the aim of the present study is to answer the question of whether any relationship exists between brain hemisphericity and general non-routine problem solving skills of prospective teachers.

\section{Materials and Methods}

\subsection{Research Design}

In this research, a descriptive survey design was used. According to Best [22]; 
"A descriptive study describes and interprets what is. It is concerned with conditions or relationships that exist, opinions that are held, processes that are going on, effects that are evident, or trends that are developing. It is primarily concerned with the present, although it often considers past events and influences as they relate to current conditions."

\subsection{Participants}

Thirty-eight prospective math teachers and 85 prospective elementary teachers participated in the study. Before this study was carried out, the first group had taken a one-term elective course about problem solving. The second group had been taught a unit on problem solving in the scope of a course about math teaching, and this instruction lasted for 12 lesson-hours. In other words, all participants had enough information about concepts of problem and problem solving, problem solving phases, classification of problems and problem solving strategies prior to the current study. All participants were juniors within the Faculty of Education.

\subsection{Instruments}

Two instruments were used in this research: The Brain Hemisphericity Inventory (BHI) and Non-routine Problem Solving Test (NPST).

Adapted by Davis, Nur and Ruru [23] and consisting of 39 items, the BHI was translated into Turkish by Kok [24]. Reliability and validity of the translated version of the BHI were also carried out by the same author. For content and face validity, Kok [24] first obtained the views of three field experts who had known and previously used the BHI before. Then the BHI was translated into Turkish by four different people and the final Turkish form of the BHI was commonly agreed upon. Afterwards, Kok [24] conducted the Turkish and English versions of the BHI on four groups including 200 prospective teachers in total. The first group took a version of the BHI in which the first 20 items were in English and the other items were in Turkish. For the second group, a version of the BHI in which the first 20 items were in Turkish and the other items were in English was implemented. The third group took a completely English version of the BHI, while a completely Turkish version of the BHI was applied to the fourth group. Finally, this process was repeated three weeks later, and then cross checks were carried out. As to reliability, by applying the test-retest method to another group of English prospective teachers, Kok [24] computed the Cronbach's Alpha coefficient of the final Turkish form of the BHI as .87.

Each item in the BHI has three options as A, B, and C. To calculate the brain dominance score of each student, first the number of $\mathrm{A}, \mathrm{B}$ and $\mathrm{C}$ options preferred by a student was counted and the number of A's was subtracted from the number of B's. If the number of C's was greater than or equal to 17, the number of B's minus A's was divided by 3 and rounded to the closest integer. If the number of C's was between 10-16, the number of B's minus A's was divided by 2 and rounded to the closest integer. If the number of C's was smaller than 10 , the number of B's minus A's was used as it was. After scoring, the students having a negative score were categorized as left-brained and the students having a positive score were categorized as right-brained. Lastly, students who obtained zero points were classified under the whole-brained category. A more detailed classification is as follows:

0 : Uses both hemispheres equally

1 to -3 : Slight Left

4 to -6 : Moderate Left

7 to -9 : Dominant Left

10 to -11: Very Strongly Dominant Left

1 to 3: Slight Right

4 to 6: Moderate Right

7 to 9: Dominant Right

10 to 11: Very Strongly Dominant Right

Constructed by the authors of the current study, the NPST consists of 9 open-ended non-routine problems. Possible strategies for each problem in the NPST are listed in Table 1.

Table 1. Possible strategies for each problem in NPST

\begin{tabular}{cc}
\hline $\begin{array}{c}\text { Number of } \\
\text { problem }\end{array}$ & Strategies \\
\hline 1,2 & Make a drawing, look for a pattern, simplify the \\
problem \\
3,9 & Work backward \\
4,5 & Guess and check \\
7,8 & Make a systematic list \\
6 & Reasoning \\
\hline
\end{tabular}

Each answer in the NPST was scored between 0 and 10 based on the rubric explained in Table 2.

Table 2. Rubric for Scoring NPST

\begin{tabular}{cc}
\hline Type of answer & Score \\
\hline No or unrelated answer & $0-2$ \\
More related but incomplete answer & $3-5$ \\
Correct strategy use but wrong or incomplete answer & $6-8$ \\
Correct strategy use and complete answer & $9-10$ \\
\hline
\end{tabular}

As an example, three answers from three different participants to the first question of the NPST (How many angles are formed by 10 distinct rays with a common endpoint?) are presented in Figure 1. Their scores for this question are 0,5 and 10 respectively. 

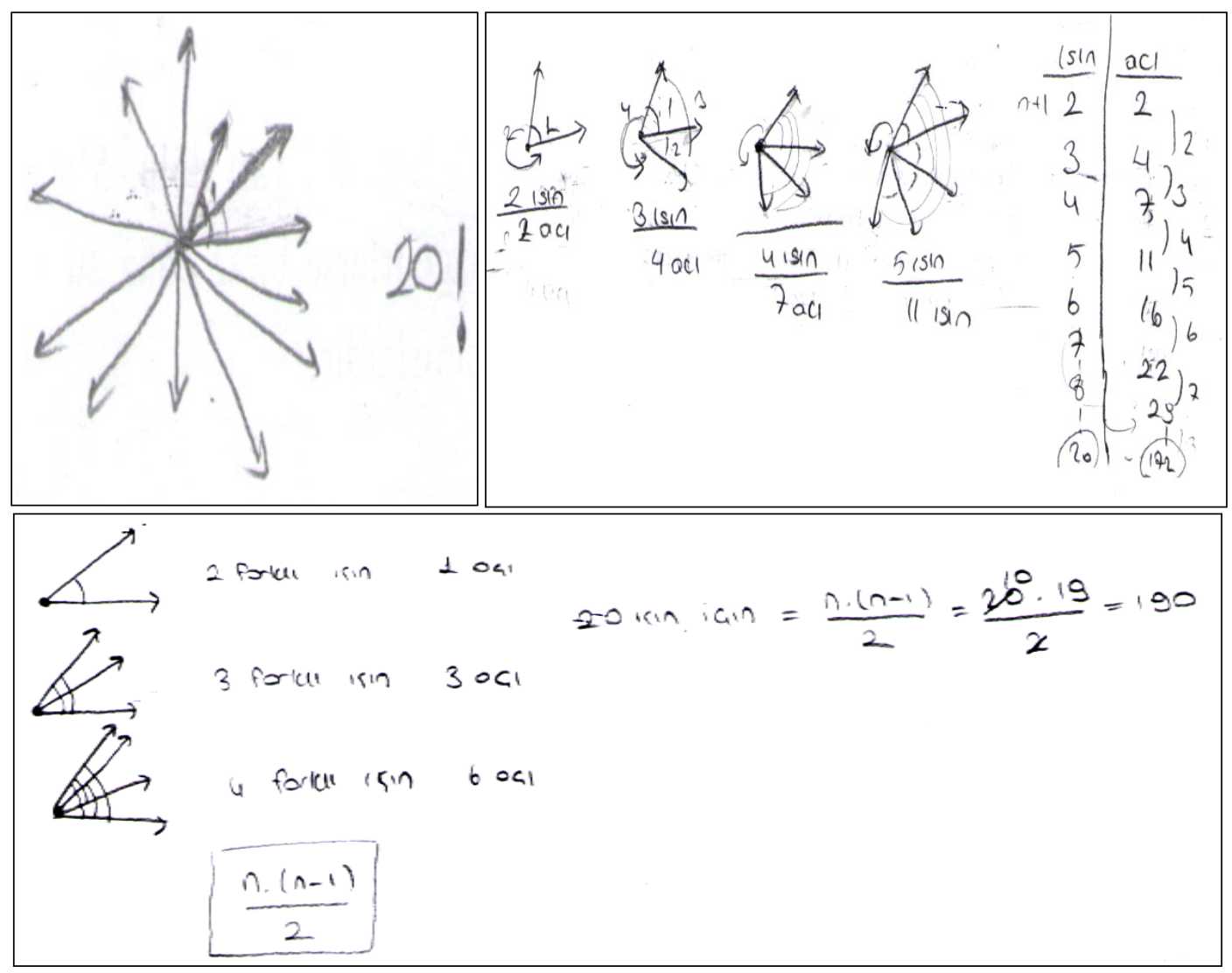

Figure 1. Three answer samples for the first problem in NPST.

\subsection{Implementation}

First the NPST and then the BHI were successively conducted on the participants. This procedure took approximately one and a half hours. During implementation of the NPST, the participants were asked to write down all their in order to provide in-depth information about their solution processes. Nothing was imposed on them about the solutions of the problems, but some explanations were provided to them if they had difficulty in understanding the problem on which they were working.

\subsection{Data analysis}

Table 3. Kolmogorov- Smirnov normality test results

\begin{tabular}{ccc}
\hline & Statistic & Sig. \\
\hline BHI & .153 & $.000^{*}$ \\
NPST & .060 & .200 \\
\hline
\end{tabular}

*Significant at .05 level

First, frequencies and percentages for each brain dominance category were computed. For the NPST, minimum and maximum value, mean and standard deviation were calculated. The next step was to analyze whether the BHI and NPST scores of the participants were distributed normally or not. Since the total number of participants was more than $30,(\mathrm{~N}=123)$ the
Kolmogorov-Smirnov normality test was run for all data sets. Results can be seen in Table 3.

According to normality test results, one of the data sets (BHI) did not show normal distribution. Therefore, the Spearman Rank Correlation Test was used to investigate the existence of any association between brain hemisphericity and non-routine problem solving skills of the prospective teachers. Raw (uncategorized) BHI scores were used for normality and Spearman Rank Correlation Test.

\section{Findings}

Table 4. Descriptive statistics about brain dominance categories

\begin{tabular}{ccc}
\hline Brain Hemisphericity & Frequency & Percentage \\
\hline Both equally & 26 & 21.2 \\
Slight Left & 44 & 35.8 \\
Moderate Left & 5 & 4.1 \\
Dominant Left & 0 & 0 \\
Very Strongly Dominant Left & 3 & 2.4 \\
Slight Right & 31 & 25.2 \\
Moderate Right & 10 & 8.1 \\
Dominant Right & 3 & 2.4 \\
Very Strongly Dominant & 1 & .8 \\
Right & 123 & 100 \\
Total & &
\end{tabular}


It was considered better to give an overview of the participants' brain hemisphericity by means of frequencies and percentages within each category. Results are presented in Table 4.

As understood from Table 4, $82.2 \%$ of the participants are situated in the slight left, both equally and slight right categories. In other words, most of the participants use both hemispheres equally or almost equally.

To obtain general information about the participants' success in non-routine problem solving, descriptive statistics based on scores obtained from the NPST were used. Results can be seen in Table 5 .

Table 5. Descriptive statistics about NPST scores of participants

\begin{tabular}{cccccc}
\hline & $\mathrm{N}$ & Minimum & Maximum & Mean & SD \\
NPST & 123 & 15 & 90 & 57.41 & 15.520 \\
\hline
\end{tabular}

It can be inferred from the results in Table 5 that the participants' success in non-routine problem solving is not very high, but above average.

Table 6. Spearman Rank Correlation Test results

\begin{tabular}{cccc}
\hline & & BHI & NPST \\
\hline \multirow{2}{*}{ BHI } & Correlation coefficient & 1,000 & .082 \\
& Sig. (2-tailed) &. & .367 \\
\multirow{2}{*}{ NPST } & Correlation coefficient & .082 & 1.000 \\
& Sig. (2-tailed) & .367 &. \\
\hline
\end{tabular}

\begin{tabular}{|c|c|c|}
\hline \multirow{2}{*}{$\begin{array}{l}1 \rightarrow 15,8,3,1 \\
2 \rightarrow X, 1 / 4\end{array}$} & $10 \rightarrow 6,15$ & $1 \rightarrow 15$ \\
\hline & $H \rightarrow \infty, 14$ & $2 \rightarrow 14$ \\
\hline $3 \rightarrow 1,6,13$ & $12 \rightarrow 4,13$ & $3 \rightarrow 13$ \\
\hline$u \rightarrow \not, \pi$, & $13 \rightarrow 3,1 x$ & $4 \rightarrow 12$ \\
\hline $5 \rightarrow 4,11$ & $116 \rightarrow 211 x$ & $5 \rightarrow 11$ \\
\hline $6 \rightarrow 3,10$ & $15 \rightarrow 1,10$ & $6 \rightarrow 10$ \\
\hline $7 \rightarrow 2,9,12$ & $16 \rightarrow 9$ & $7 \rightarrow 18$ \\
\hline $8 \rightarrow 1,8,17$ & $17 \rightarrow 8$ & $8 \rightarrow 17$ \\
\hline$x \rightarrow 10,+$ & $18 \rightarrow 7$ & $3 \rightarrow B$ \\
\hline
\end{tabular}

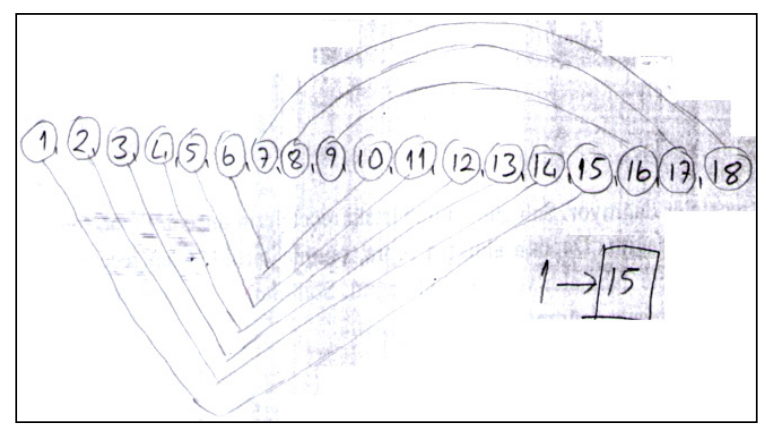

Figure 2. Samples of answers from very strongly dominant right- and left-brained students.

Since this study mainly aims at determining any linkage between non-routine problem solving and brain hemisphericity, results of the Spearman Rank Correlation Test are important and decisive. According to the values represented in Table 6, the correlation coefficient was not statistically significant (correlation coefficient $=.082 ; \mathrm{p}$ $=.367 ; \mathrm{p}>.05$ ). That is, there is no meaningful relationship between cerebral dominance and success in non-routine problem solving.

In Figure 2, there are two samples of answers given for the seventh problem in the NPST (see Appendix B). As stated in the Introduction section, right-brained people are more visuo-spatially oriented while left-brained people tend to be more analytical and logical. However, the first answer in Figure 2 was given by a very strongly dominant right-brained student, and she benefited from a written, logical explanation strategy (make a systematic list) contrary to expectations. Besides, the second student solved the problem by using a visual strategy (make a drawing) although he was very strongly dominant left-brained. That is to say, these students applied strategies which were not in accord with their brain hemisphericity. This qualitative evidence reinforces the finding which indicates disconnection between the variables of this study.

\section{Discussion}

As Creswell, Gifford and Huffman [18] emphasized, the brain operates with the best capacity when the cognitive processes which the problem demands are of sufficient complexity to activate both hemispheres. Thus, simple, repetitive and uninteresting, namely routine problems will be poorly learned, with little benefit for either hemisphere. This was the main reason for choosing non-routine problems for the current study. The most important contribution of this study to the literature is the finding that achievement in non-routine problem solving does not depend on brain dominance. Fernandez [1] also achieved a similar finding which demonstrates no significant differences exist among mathematics achievement of students when their brain hemisphericity is taken into consideration.

There is one point that needs to be highlighted here: This research has been designed as a descriptive study. However, effects of the course during which participants encountered non-routine problems and strategies that can be exploited to solve these problems should not be ignored. Even though it did not last for a long time, brain hemisphericity of students may have been affected at the end of the course. For example, a student who did not use the make a drawing strategy very effectively at the beginning of the course may increasingly have referred to it throughout the course. Taking into consideration that this strategy requires more activation of the right hemisphere, it can be said that this student was able to expand his repertoire of strategies during the course and thus begin to use his non-dominant sphere more actively. This factor should be kept in mind while the results of this study are interpreted.

As for educational implication of the results, the main 
finding of this study may imply that left- or right-brained students can be equally successful in non-routine problem solving. Besides, it can encourage pre-service and in-service teachers to use non-routine problems in math teaching without any limitation in the sense of brain dominance. Based on this, more time and place can be allocated for non-routine problems in text-books and learning environments.

The limitations of this study and recommendations for future studies should be mentioned as well. With comparatively large numbers of students from different ages or grade levels, better results or validation of the results suggested here may be attainable. Including preand posttest, an experimental design with a control group may provide in-depth information about the question of whether such an intervention affects the linkage between brain hemisphericity and achievement in non-routine problem solving. Moreover, the brain hemisphericity of the participants was mostly accumulated in the slight left, both equally and slight right categories. Numbers of participants in extreme categories such as dominant right or very strongly dominant left were quite low. In future studies, equal numbers of participants should be selected for each category. Data obtained from such a sample will be more detailed and sounder. Lastly, in addition to a paper-and-pencil-based test, a different method such as neuroimaging or visual field tests may provide more certain knowledge on brain hemisphericity of participants.

\section{Appendix}

\section{Appendix A: Sample Items from the BHI}

\section{3: I am:}

a Easily lost when finding directions, especially if I have never been to that place before.

b Good at finding my way, even when I have never been in that area.

c not bad at finding directions, but not really good either

18. I am good at:

a Explaining things mainly with words.

$\mathrm{b}$ Explaining things with hand movements and actions.

c Doing both equally well.

\section{Appendix B: Sample Problems from NPST}

3) Fidan delivers prescriptions for the local pharmacy. On Tuesday, she delivered 5/9 of the prescriptions already in the delivery van and then $3 / 4$ of the remaining prescriptions. After picking up 10 more prescriptions at the store, she delivered $2 / 3$ of those she had with her. She then picked up an additional 12 prescriptions and then delivered the remaining 5 prescriptions. How many prescriptions did she deliver?

7) Julide invited 17 friends to a dinner party at her house last Friday evening. She gave each guest a card with a number from 2 through 18, reserving number 1 for herself. When she had everyone paired off at the dinner table, she noticed that the sum of each couple's number was a perfect square. What number did Julide's partner have?

\section{REFERENCES}

[1] Fernandez, S. F. (2011). Brain hemisphericity and mathematics achievement of high school students. Unpublished Master of Arts in Education (Mathematics) Thesis, West Visayas State University, Iloilo City.

[2] Lee, K. (2003) Neuroscience and education: Promises and pitfalls. Asia Pacific Journal of Education, 23(2), 109-119

[3] Hariyani S., Yuwono I., Sa'dijah C. \& Rahardjo S. (2016). Math problem solving phases on thinking outside the box. IOSR Journal of Research \& Method in Education (IOSR-JRME), 6(4), 43-48.

[4] Gokulakrishnan C., Kumar C., A., \& Adaikalaraj, R. (2015). Brain dominance in creativity, intelligence and academic achievement of high school students. Shiv Shakti International Journal of Multidisciplinary and Academic Research, 4(5)

[5] Oxford, R., Ehrman, M., \& Lavine, M. (1991). Style wars: Teacher-student style conflicts in the language classroom. In S. S. Magnon (Ed.), Challenges in the 1990s for College Foreign Language Programs (pp. 1-25). Boston, Mass: Heinle \& Heinle Publishers.

[6] Roubinek, D. L., Bell, M. L., \& Cates, L. A. (1987). Brain hemispheric preference of intellectually gifted children. Roeper Review: A Journal on Gifted Education, 10(2), 120-122.

[7] Liederman, J. \& Kinsbourne, M. (1980). The mechanism of neonatal rightward turning bias: A sensory or motor asymmetry? Infant Behavior and Development. 5,223-303.

[8] Stellern, J., Collins, J., Gutierrez, B. \& Patterson E. (1986, January). Hemispheric dominance of Native American Indian students. Journal of American Indian Education, $8-18$.

[9] Saleh, A., \& Iran-Nejad, A. (1995). Wholetheme constructivism and whole-brain education: Educational implications of the research on left and right brain hemispheres. Annual Meeting of the Mid-South Educational Research Association, Biloxi, MS.

[10] Polya, G. (1957). How to solve it: A new aspect of mathematical method (2nd Ed.). New York: Double Day and Co.

[11] Schoenfeld, A. H. (1992). Learning to think mathematically: Problem-solving, metacognition and sense-making in mathematics. In D. Grouws (Ed.), Handbook for Research on Mathematics Teaching and Learning (pp. 334-370). New York: Mac Millian. 
[12] Cai, J. (2003). Singaporean students' mathematical thinking in problem-solving and problem posing: An exploratory study. International Journal of Mathematical Education in Science and Technology, 34(5), 719-737.

[13] Woodward, J., Beckmann, S., Driscoll, M., Franke, M., Herzig, P., Jitendra, A., Koedinger, K. R., \& Ogbuehi, P. (2012). Improving mathematical problem-solving in Grades 4 through 8: A practice guide. Washington, D.C.: National Center for Education Evaluation and Regional Assistance, Institute of Education Sciences, U.S. Department of Education.

[14] Nancarrow, M. (2004). Exploration of metacognition and non-routine problem based mathematics instruction on undergraduate student problem solving success, Unpublished $\mathrm{PhD}$ thesis, the Florida State University, Florida.

[15] Herr, T. \& Johnson, K. (2002). Problem-solving strategies: Crossing the river with dogs. USA: Key Curriculum Press.

[16] Leng, N. W. (2008). Problem solving heuristics for primary school mathematics: A comprehensive guide. Singapore: Prentice Hall.

[17] Posamentier, A. S. \& Krulik, S. (2008). Problem solving strategies for efficient and elegant solutions, grades 6-12: A resource for the mathematics teacher. USA: Corwin Press

[18] Creswell, J. L., Gifford, C. and Huffman, D. (1988),
Implications of right/left brain research for mathematics educators. School Science and Mathematics, 88: 118-131.

[19] Grabner, R. H., Ansari, D., Koschutnig, K. \& Reishofer, G. (2009). To retrieve or to calculate? Left angular gyrus mediates the retrieval of arithmetic facts during problem solving. Neuropsychologia, 47, 604-608.

[20] Newman, S. D., Carpenter, P. A., Varma, S. \& Just M. A. (2003). Frontal and parietal participation in problem solving in the tower of London: fMRI and computational modeling of planning and high-level perception. Neuropsychologia, $41,1668-1682$.

[21] Oliver, E. M. (2009). Relationships between problem solving strategies and brain hemisphericity in high school students. Honors thesis, Texas University, San Marcos, Texas.

[22] Best, J. W., \& Kahn, J. V. (2006). Research in education (10th Ed.). Boston: Pearson Education, Inc.

[23] Davis E. C. E., Nur H. \& Ruru S. A. A. (1994). Helping teachers and students understand learning styles. English Teaching Forum, 32 (3), 12-27.

[24] Kok, I. (2005). An investigation into the effects of teaching based on the principles of Neuro-linguistic Programming and the traditional methods on the students' attitudes towards learning English and their academic achievements. Unpublished PhD. Thesis, Dokuz Eylul University, Izmir 